\title{
Synthesis and properties of polyelectrolyte multilayered microcapsules reinforced smart coatings
}

\author{
Adnan Khan ${ }^{1,5}$, Fareeha Ubaid ${ }^{1}$, Eman M. Fayyad ${ }^{1,6}$, Zubair Ahmad $^{1}$, R. A. Shakoor ${ }^{1, \star}$ (D), \\ M. F. Montemor ${ }^{2}$, Ramazan Kahraman ${ }^{3}$, Said Mansour ${ }^{4}$, Mohammad K. Hassan ${ }^{1}$, \\ Anwarul Hasan ${ }^{5}$, and Aboubakr M. Abdullah ${ }^{1}$ \\ ${ }^{1}$ Center for Advanced Materials, Qatar University, 2713 Doha, Qatar \\ ${ }^{2}$ Centro de Química Estrutural, Instituto Superior Técnico, Universidade de Lisboa, Av. Rovisco Pais, 1049-001 Lisbon, Portugal \\ ${ }^{3}$ Department of Chemical Engineering, Qatar University, 2713 Doha, Qatar \\ ${ }^{4}$ Qatar Energy and Environment Research Institute, Hamad Bin Khalifa University, Qatar Foundation, 34110 Doha, Qatar \\ ${ }^{5}$ Department of Mechanical and Industrial Engineering, Qatar University, 2713 Doha, Qatar \\ ${ }^{6}$ Physical Chemistry Department, National Research Centre, P.O. Box 12622, Dokki, Giza, Egypt
}

Received: 7 March 2019

Accepted: 4 June 2019

Published online:

17 June 2019

(C) The Author(s) 2019

\begin{abstract}
The present research work focuses on the synthesis, characterization and properties of novel polyelectrolyte multilayered microcapsules used as smart additives in organic coatings for corrosion protection of steel parts. Urea formaldehyde microcapsules encapsulated with linalyl acetate (UFMCs), sensitive to mechanical stimulus, were synthesized by in situ emulsion polymerization technique. In the next step, dodecylamine, working as a $\mathrm{pH}$ stimulus corrosion inhibitor, was loaded into layers of polyelectrolyte molecules, polyethylenimine (PEI) and sulfonated polyether ether ketone (SPEEK). These were applied layer-by-layer over the microcapsules to form inhibitor containing multilayered urea formaldehyde microcapsules (MLUFMCs). In the next step, MLUFMCs (5.0 $\mathrm{wt} \%$ ) and UFMCs $(5.0 \mathrm{wt} \%$ ) were thoroughly dispersed into the epoxy resin and coated on cleaned steel. A comparison of the structural, thermal and anticorrosive properties indicates that coatings modified with multilayered capsules (PMLSCs) demonstrate good thermal stability, improved self-healing characteristics and higher corrosion resistance compared to the coating modified with urea formaldehyde microcapsules. The improved properties of PMLSCs can be attributed to efficient release of the encapsulated self-healing agent and corrosion inhibitor from the MLUFMCs. Therefore, epoxy coatings modified with the novel multilayered capsules may be attractive for corrosion protection of steel parts used in oil and gas and related industries.
\end{abstract}

Address correspondence to E-mail: shakoor@qu.edu.qa 


\section{Introduction}

Corrosion is one of the primary concerns faced by many industries which cause significant financial damages, wastage of time, efforts and natural resources. In severe situations, corrosion damages may lead to safety threats as well [1]. One of the most effective ways to protect metallic parts from corrosion is by applying organic coatings. Different types of organic coatings have been developed and tested for anticorrosion applications, and it has been demonstrated that the protection depends on the presence of effective anticorrosion pigments and barrier layer efficacy. However, abrasion, microscratches, pores and pinholes contribute significantly to cause failures of the protective coatings [2]. During operation, once the barrier layer is disrupted due to any reason, the degradation of the coated metal progresses rapidly. The aforementioned problems can be mitigated and the coating anticorrosive performance can be further enhanced through the application of smart additives. Smart additives-containing coatings, also known as smart coatings, can sense local environmental changes and respond to those stimuli accordingly [3]. Smart coatings have been synthesized and studied by several research groups $[4,5]$. Smart coatings can provide self-healing of the polymeric matrix $[4,6-8]$ or/and healing of the corrosion process [9-14]. Under specific stimulus conditions, the active agents stored into nano/microcontainers can be released to heal the coating or to inhibit corrosion activity. As an example, self-healing coatings containing film forming agents such as linseed oil [15, 16], tung oil [4], silanes [17] and epoxy [6] loaded in carriers can heal micro-scratches and defects by forming a stable film in the defective area $[5,7,16,18,19]$.

The performance of smart coatings is highly influenced by the nature of the nano/micro-containers that work as storage reservoirs and that can sense certain stimuli $[20,21]$ such as mechanical load [17], temperature [22], light and $\mathrm{pH}$ gradients [7, 23] that are expected to tune the release of the active species. For example, polymerizable species released thanks to capsules rupture can react either with the coating matrix [8], water [24] or oxygen [9], depending on the nature and type of the active agent. The polymerization of the active agents in coating defects repairs the coating and prevents corrosion $[8,17]$.
Another important and reliable trigger is based on $\mathrm{pH}$ gradients [25, 26]. $\mathrm{pH}$-sensitive containers loaded with corrosion inhibitors can be activated by local $\mathrm{pH}$ gradients associated with the corrosion activity and release the inhibitor into these active areas, protecting the metal. $\mathrm{ZnO}$ [10], $\mathrm{SiO}_{2}$ nanoparticles [11], halloysite nanotubes $[27,28], \mathrm{TiO}_{2}$ nanotubes $[29,30]$ and others have been used as $\mathrm{pH}$-sensitive carriers of corrosion inhibitors. As an advancement, the use of multiple containers sensitive to similar or distinct stimuli, in a single polymeric coating, has gained significant attention and claimed as more effective corrosion protection route [31, 32]. However, very recently, instead of using multiple containers, double-stimuli-responsive smart microcapsules have been reported as a novel route to mitigate corrosion, while reducing the cost of the protective coating [33].

In the present work, novel polyelectrolyte multilayered microcapsule, with double-stimuli response, is proposed as additives for epoxy coatings to enhance corrosion protection of steel. Ureaformaldehyde microcapsules loaded with linalyl acetate (self-healing agent) were synthesized by in situ emulsion polymerization (UFMCs). Linalyl acetate is released when mechanical stimulus, i.e., an artificial crack is created. Furthermore, dodecylamine, a corrosion inhibitor, was entrapped into the layers of polyelectrolyte materials (PEI and SPEEK), using the layer-by-layer technique to develop $\mathrm{pH}$ sensitive multilayered urea formaldehyde microcapsules (MLUFMCs) [33-37]. The results evidence that coatings modified with MLUFMCs provided increased corrosion resistance. The improvement in corrosion resistance can be attributed to the chemistry of the novel multilayered formulation. In case of SPEEK, deposited as a polyelectrolyte layer, the degree of sulfonation is much higher; hence, the interaction between the polyelectrolyte layers deposited in the current study will be stronger as compared to other polyelectrolyte materials already reported in the literature. This strong interaction between the polyelectrolyte layers will facilitate the entrapment of inhibitor which will be clearly shown in the TEM images presented in the results. The autoxidation phenomenon of linalyl acetate with the atmospheric oxidation makes it more efficient and spontaneous to use a self-healing agent as compared to other self-healing materials already reported, i.e., linseed oil and tung oil, etc. Dodecylamine is an efficient corrosion inhibitor especially in the acidic 
medium, and the sustained and controlled release of DOC, in response to an external stimuli, makes it effective to use in the current polyelectrolyte multilayered formulation.

\section{Experimental section}

\section{Materials}

All the required chemicals, which include urea, ammonium chloride, resorcinol, hydrochloric acid, sodium hydroxide, $37 \mathrm{wt} \%$ formaldehyde, ethylenemaleic anhydride copolymer (EMA), dodecylamine, ethanol, sulfonated polyether ether ketone (SPEEK), linalyl acetate and sodium chloride, were purchased from Sigma-Aldrich. Epofix resin along with diethylenetriamine employed as hardener for the resin, dimethylacetamide and polyethylenimine (PEI) were purchased from BDH Chemicals Ltd. Cleaned and polished carbon steel sheet was used as substrates.

\section{Synthesis of urea formaldehyde microcapsules encapsulated with linalyl acetate (LA)}

Urea formaldehyde microcapsules encapsulated with linalyl acetate were synthesized by in situ emulsion polymerization method as reported by Brown et al. [38]. A schematic diagram of the experimental set up is presented in Fig. 1. During this process, $200 \mathrm{ml}$ of deionized water was mixed with $50 \mathrm{ml}$ of aqueous solution of EMA (25 wt\%). Later, $5.0 \mathrm{~g}$ urea, $0.5 \mathrm{~g}$ of ammonium chloride and $0.5 \mathrm{~g}$ of resorcinol were added to the solution and thoroughly mixed using an overhead mechanical stirrer to form a homogenous solution. The $\mathrm{pH}$ of the solution was adjusted at approximately 3.0 using $\mathrm{NaOH}$ and/or $\mathrm{HCl}$. After maintaining the desired $\mathrm{pH}, 50 \mathrm{ml}$ of linalyl acetate was added to the solution and left to stabilize for $10 \mathrm{~min}$ under continuous stirring at $400 \mathrm{rpm}$. This stirring resulted in homogeneous mixing of the ingredients. Then $13.0 \mathrm{~g}$ of aqueous formaldehyde $(37.0 \mathrm{wt} \%)$ was added to the solution, and the temperature was slowly increased until it reached to $55{ }^{\circ} \mathrm{C}$, leading to encapsulation of linalyl acetate into the urea formaldehyde. The temperature of the solution was kept constant during the entire encapsulation process using a temperature-controlled water bath. After obtaining the desired encapsulation temperature $\left(55^{\circ} \mathrm{C}\right)$, the stirring speed was increased to $1000 \mathrm{rpm}$ to obtain medium size of the urea formaldehyde microcapsules encapsulated with linalyl acetate (UFMCs). It is pertinent to mention here that size of UFMCs is highly influenced by the stirring speed. The continuous stirring of the solution for $4 \mathrm{~h}$ employing $1000 \mathrm{rpm}$ at $55^{\circ} \mathrm{C}$ resulted in a suspension containing UFMCs. The suspension was then vacuum-filtered to obtain UFMCs, which were thoroughly rinsed with water and dried at room temperature.

\section{Synthesis of multilayered microcapsules impregnated with dodecylamine (DOC)}

The layer-by-layer technique was used to coat layers of the polyelectrolytes SPEEK and PEI on the surface of the UFMCs. The positively charged polyelectrolyte PEI was first coated on the surface of the UFMCs by mixing $40 \mathrm{ml}$ microcapsules suspension with $60.0 \mathrm{ml}$ of PEI solution $\left(2.0 \mathrm{mg} \mathrm{ml}^{-1}\right)$ for $10.0 \mathrm{~min}$ at $300 \mathrm{rpm}$. To remove the excess PEI, the mixture was centrifuged and then washed three times with distilled water. Then a negatively charged polyelectrolyte SPEEK layer was assembled on the positively charged polyelectrolyte PEI by adding $40 \mathrm{ml}$ suspension of the above prepared microcapsules (microcapsule + PEI) to $60.0 \mathrm{ml}$ of the SPEEK solution. The suspension was continuously stirred at $300 \mathrm{rpm}$ for $10 \mathrm{~min}$. Excessive amount of the SPEEK was removed through centrifuging process similar to the first layer. The SPEEK solution was formed by dissolving SPEEK in the dimethylacetamide using concentration of $2.0 \mathrm{mg} \mathrm{ml}^{-1}$ at room temperature. To completely absorb the SPEEK and to form a homogeneous solution, the mixture was stirred for $10.0 \mathrm{~min}$ at $300 \mathrm{rpm}$ [39]. The third layer, composed of positively charged dodecylamine (DOC), was prepared by adding the $40.0 \mathrm{ml}$ solution of abovesynthesized microcapsules (microcapsules + PEI + SPEEK) with the $60.0 \mathrm{ml}$ solution of dodecylamine $\left(10.0 \mathrm{mg} \mathrm{ml}^{-1}\right)$, adjusting the $\mathrm{pH}$ to 3 and stirring the mixture for $20 \mathrm{~min}$ at $300 \mathrm{rpm}$. The fourth layer, SPEEK, and the fifth layer, PEI, were deposited on the shell of the microcapsules containing DOC, respectively, using the same procedure described earlier. Finally, polyelectrolyte multilayered urea formaldehyde microcapsules (MLUFMCs) were 


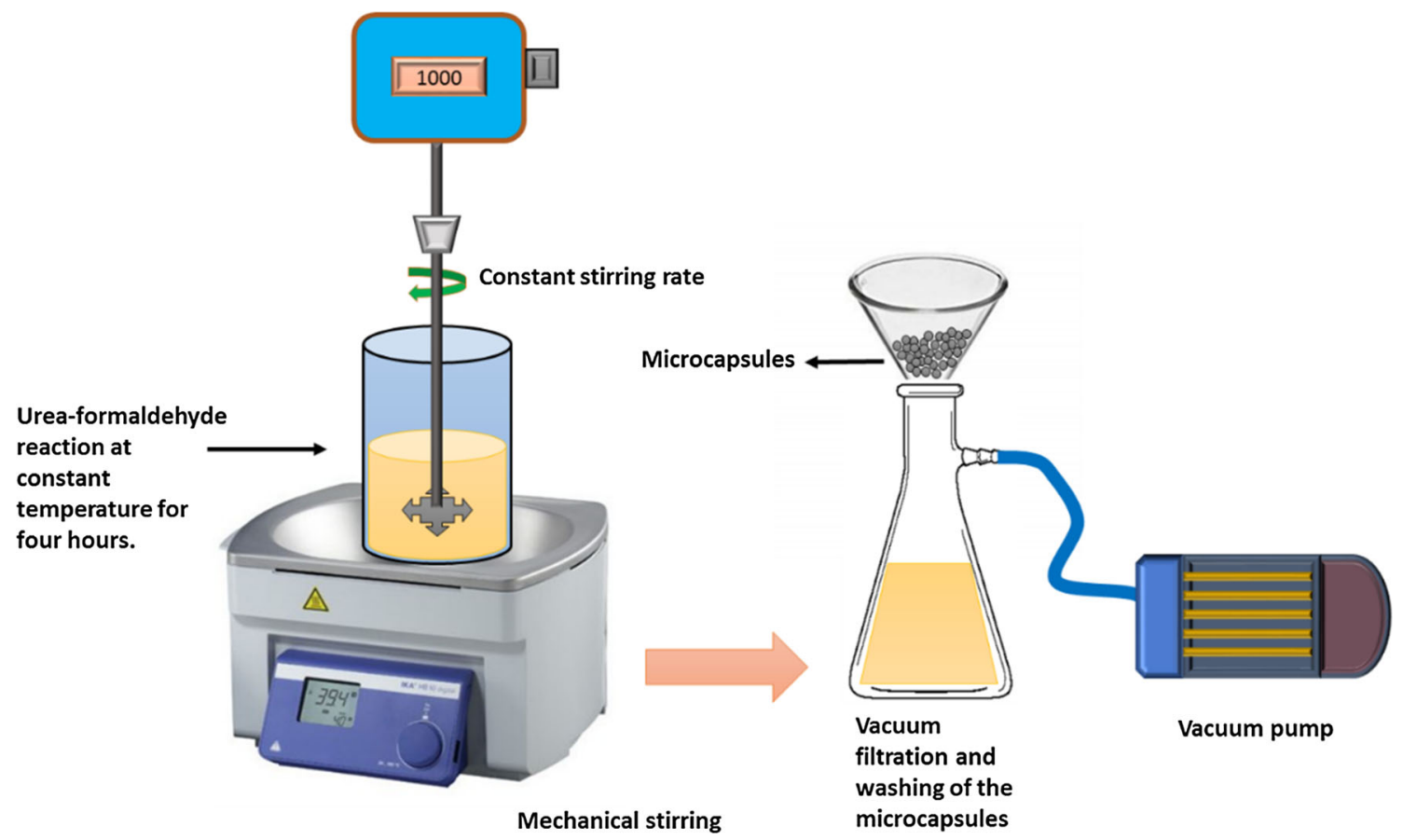

Figure 1 Schematic diagram of the experimental set up for the synthesis of encapsulated urea formaldehyde microcapsules (UFMCs).

obtained. The steps of synthesis of UFMCs are schematically shown in Fig. 2.

\section{Preparation of coated specimens}

Cleaned carbon steel specimens were ground using different SiC abrasive papers (180, 400, 800, 1000 and 1200 grits), washed with distilled water, degreased in acetone, washed again with distilled water and dried with air. For comparative purposes, three types of coatings were prepared using doctor blade technique; (1) pure epoxy coatings without any microcapsules referred as PEC (2) coatings containing UFMCs referred as SLSCs and (3) coatings containing MLUFMCs designated as PMLSCs. For a direct comparison purpose, $5.0 \mathrm{wt} \%$ of each type of microcapsules were uniformly dispersed in the epoxy, mixed with the hardener in the same stoichiometric ratio and finally sonicated for $10 \mathrm{~min}$ at room temperature to remove the air bubbles. Finally, coatings of approximately $120 \mu \mathrm{m}$ thickness were applied on cleaned carbon steel substrates using a doctor blade. The coated specimens were cured at room temperature for $24 \mathrm{~h}$. The schematic diagrams of SLSCs and PMLSCs are shown in Fig. 3.

\section{Characterization of microcapsules and coatings}

The presence of polyelectrolyte layers, self-healing species and corrosion inhibitor in the microcapsules was confirmed through FTIR analysis. The analysis was carried out using the FTIR Frontier (PerkinElmer, Frontier, USA) instrument, and the spectra were recorded in the range of 4000 to $500 \mathrm{~cm}^{-1}$. The charge of multilayers was determined employing zeta potential equipment (Malvern, Zeta sizer, Nano ZSP, USA).

The presence of polyelectrolytes layers on the surface of microcapsules and their chemical composition
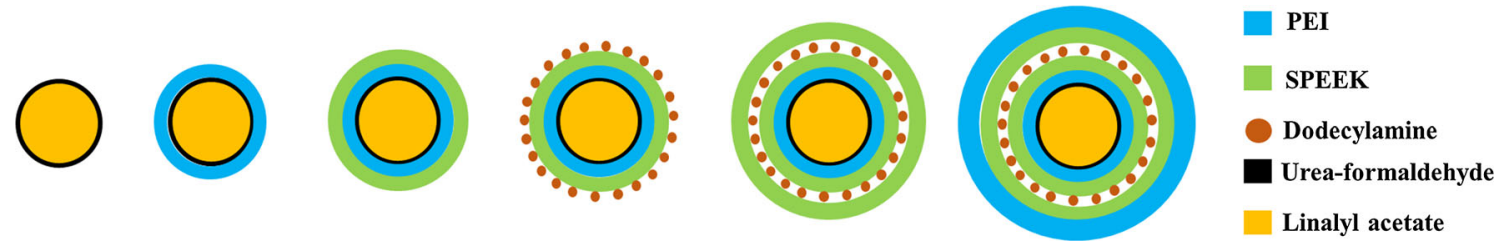

Figure 2 Schematic representation of the structure of as-synthesized layered microcapsules. 
(a)

Urea-formaldehyde microcapsules

Linalyl acetate (Mechanically triggered)

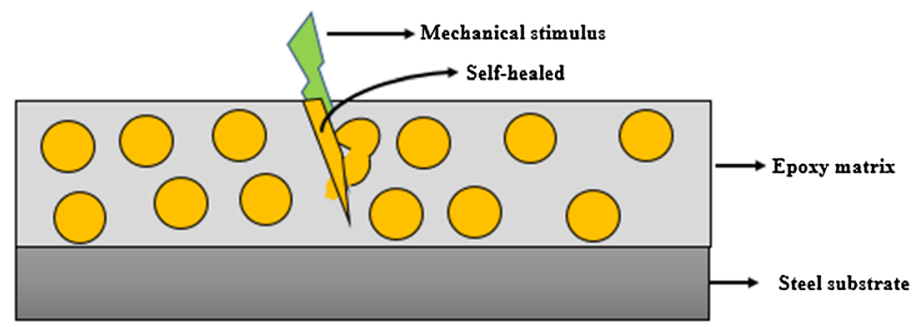

(b)

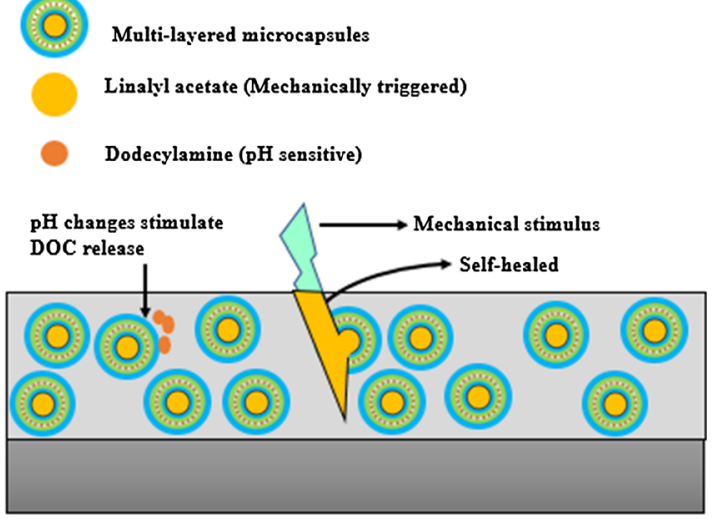

Figure 3 Schematic diagrams of smart coatings a modified with UFMCs referred to as SLSCs b modified with polyelectrolyte multilayered capsules (PMLSCs).

was further confirmed by XPS (AXIX Ultra DLD, Kratos, UK) employing monochromatic X-ray Source-Al $\mathrm{K} \alpha$ source; the binding energy of $\mathrm{C} 1 \mathrm{~s}$ $(284.6 \mathrm{eV})$ was used as reference. To determine the elemental composition, XPS survey spectra were recorded in the binding energy range of 250 to $800 \mathrm{eV}$. High-resolution spectra were recorded for C $1 \mathrm{~s}$ at an energy step size of $0.1 \mathrm{eV}$ at pass energy of $10 \mathrm{eV}$.

The surface morphology of the synthesized microcapsules UFMCs and MLUFMCs was studied by a field emission scanning electron microscope (FESEM-Nova Nano-450, Netherland) and transmission electron microscopy (TEM, FEI, TALOS F200X, USA).

The particle size distribution of the prepared microcapsules was studied using particle size analyzer (Malvern, Master sizer 2000, Panalytical, USA).

The structural and phase analysis of microcapsules was performed through X-ray diffraction analysis using a PAN analytical $X^{\prime}$ pert Pro $\mathrm{Cu}(\mathrm{K} \alpha)$, with a scanning rate of $2^{\circ} \mathrm{min}^{-1}$ and scanning angle ranging between $10^{\circ} \leq 2 \theta \leq 50^{\circ}$. A TGA synchronization analyzer (PerkinElmer, TGA 4000, USA) was used to analyze the thermal stability of the synthesized microcapsules and the developed coatings in the temperature range $30^{\circ} \mathrm{C}$ to $600{ }^{\circ} \mathrm{C}$ employing heating rate of $20{ }^{\circ} \mathrm{C} \mathrm{min}^{-1}$.

Self-release of the inhibitor encapsulated in nanocontainers was carried out by conducting UVVis spectroscopic analysis (LAMBDA $650 \mathrm{UV} / \mathrm{Vis}$ Spectrophotometer, PerkinElmer, USA). During this test, small amount of MLUFMCs (0.2 g) was added to $0.1 \mathrm{M} \mathrm{NaCl}$ solution to form a suspension. The amount of the released DOC from the MLUFMCs was measured as a function time at various $\mathrm{pH}$ values. The self-healing ability of smart coatings was evaluated using FE-SEM (FE-SEM-Nova Nano-450, Netherland).

The coatings were subjected to a controlled scratch following ASTM D1654 standard procedure and the scratch healing was recorded as a function of time. The corrosion resistance of coatings was studied by EIS in $3.5 \mathrm{wt} \% \mathrm{NaCl}$ solution using a three-electrode electrochemical cell, using the coated steel sample as working electrode and a graphite rod and $\mathrm{Ag} / \mathrm{AgCl}$ as counter and reference electrodes, respectively. The EIS analysis was carried out using a Gamry 3000 (30 K BOOSTER Potentiostat/Galvanostat/ZRA, USA). EIS experiments were conducted within a frequency range of 0.1 to $100 \mathrm{kHz}$, starting from the higher limit toward the lower one, at OCP, and the rms signal was $10 \mathrm{mV}$.

\section{Results and discussion}

\section{FTIR analysis of microcapsules and coatings}

FTIR analysis confirmed encapsulation of linalyl acetate in urea formaldehyde microcapsules and the loading of dodecylamine in the polyelectrolyte layers. Figure $4 a, b$ shows the FTIR spectra of UFMCs and pure linalyl acetate. The broad absorption band at $3320 \mathrm{~cm}^{-1}$ shows overlapping of the $\mathrm{O}-\mathrm{H}$ bond and $\mathrm{N}-\mathrm{H}$ bonds and can be ascribed to urea-formaldehyde. The $\mathrm{O}-\mathrm{H}$ bond is shifted to the right side due to the strong $\mathrm{C}=\mathrm{O}$ dipole force of encapsulated linalyl acetate in the UFMCs. The small sharp peak at 


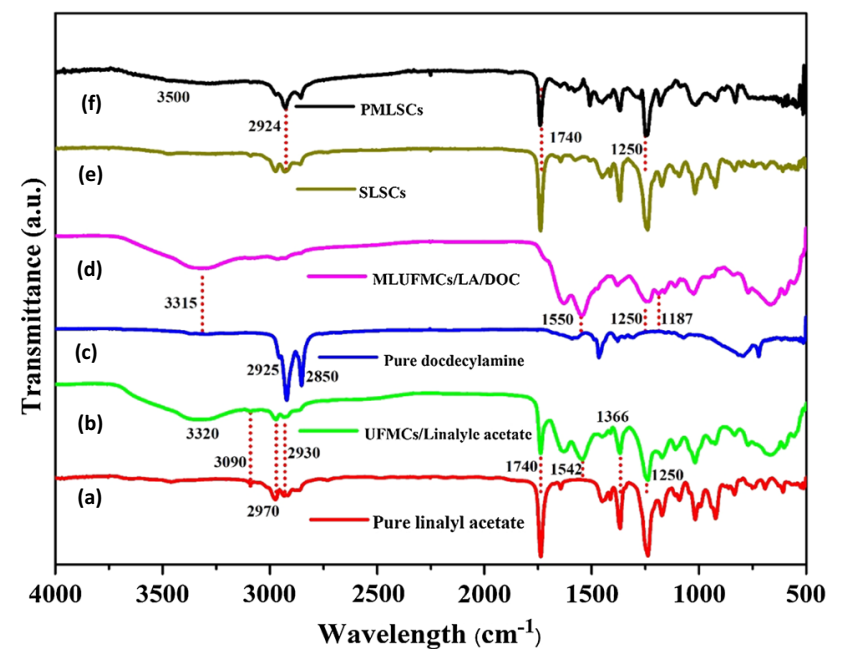

Figure 4 FTIR spectra of the microcapsules and coatings (a, b) as-synthesized UFMCs encapsulated with linalyl acetate and pure linalyl acetate (c, d) MLUFMCs and pure dodecylamine (e, f) PMLSCs and SLSCs.

$3090 \mathrm{~cm}^{-1}$ represents the $\mathrm{C}-\mathrm{H}$ bands, while peaks at $2970 \mathrm{~cm}^{-1}$ and $2930 \mathrm{~cm}^{-1}$ show the presence of $\mathrm{C}-\mathrm{H}_{3}$ and the sharp peak at $1740 \mathrm{~cm}^{-1}$ represents the carbonyl $\mathrm{C}=\mathrm{O}$ bands, which can be associated with linalyl acetate and urea formaldehyde. All these bands confirm the presence of linalyl acetate. However, there is a new peak at $1542 \mathrm{~cm}^{-1}$ representing the $\mathrm{N}-\mathrm{H}$ band and it accounts for the presence of urea-formaldehyde. Moreover, the peak at $1366 \mathrm{~cm}^{-1}$ also represents a $\mathrm{C}-\mathrm{H}$ band with different vibration, while the peak at $1250 \mathrm{~cm}^{-1}$ corresponds to the $\mathrm{C}-\mathrm{N}$ band. It can be noticed that the $\mathrm{C}-\mathrm{H}$ and $\mathrm{C}-$ $\mathrm{N}$ vibrations are present in both UFMCs and pure linalyl acetate. The presence of corresponding distinctive absorption bands of $\mathrm{N}-\mathrm{H}$ at $1542 \mathrm{~cm}^{-1}$ (urea formaldehyde), $\mathrm{C}=\mathrm{O}$ at $1740 \mathrm{~cm}^{-1}$ (linalyl acetate) and $\mathrm{C}-\mathrm{N}$ at $1250 \mathrm{~cm}^{-1}$ (linalyl acetate) in the UFMCs confirms efficient storage of linalyl acetate.

Figure $4 c$, d shows the FTIR spectra of pure dodecylamine (DOC) and MLUFMCs. The broad peak at $3315 \mathrm{~cm}^{-1}$ in the MLUFMCs spectrum and a minor sharp peak in the spectrum of pure DOC corresponds to the $\mathrm{N}-\mathrm{H}$ bonding. The two sharp peaks at $2925 \mathrm{~cm}^{-1}$ and $2850 \mathrm{~cm}^{-1}$ represent the $\mathrm{C}-\mathrm{H}$ bonds in DOC and MLUFMCs; however, the peak intensity is high in DOC because of the long $\mathrm{C}-\mathrm{H}$ chain in the structure of DOC. The peaks present at $1550 \mathrm{~cm}^{-1}$ and $1187 \mathrm{~cm}^{-1}$ represent $\mathrm{C}=\mathrm{C}$ and $\mathrm{C}-\mathrm{O}$ bonds, respectively, which confirms the presence of SPEEK layer on the surface of MLUFMCs. Similarly, the peak at
$1250 \mathrm{~cm}^{-1}$ can be ascribed to C-N band, which clearly demonstrates the existence of a PEI layer on the MLUFMCs. The presence of corresponding distinctive absorption bands of $\mathrm{N}-\mathrm{H}$ at $3315 \mathrm{~cm}^{-1}$ (DOC), $\mathrm{C}=\mathrm{C}$ at $1550 \mathrm{~cm}^{-1}$ and $\mathrm{C}-\mathrm{O}$ band at $1187 \mathrm{~cm}^{-1}$ (SPEEK) and $\mathrm{C}-\mathrm{N}$ at $1250 \mathrm{~cm}^{-1}$ (PEI) confirms the formation of MLUFMCs and efficient encapsulation of DOC. It is pertinent to note that $\mathrm{C}-\mathrm{N}$ band at $1250 \mathrm{~cm}^{-1}$ overlaps with linalyl acetate as reported previously [40].

Figure 4e, $\mathrm{f}$ indicates the FTIR spectrum of PMLSCs and SLSCs. A comparison of FTIR spectra of PMLSCs, SLSCs, UFMCs and MLUFMCs confirms their identical nature. The multiple small peaks present at $2924 \mathrm{~cm}^{-1}$ represent the $\mathrm{C}-\mathrm{H}$ bond and associated with DOC and MLUFMCs. The $\mathrm{C}=\mathrm{O}$ bond at $1750 \mathrm{~cm}^{-1}$ represents the carbonyl $\mathrm{C}=\mathrm{O}$ group which can be associated with linalyl acetate and urea form aldehyde. Moreover, the sharp peak at $1250 \mathrm{~cm}^{-1}$ represents the $\mathrm{C}-\mathrm{N}$ bond that can be ascribed to urea form aldehyde, DOC and PEI. A small intensity peak at $3500 \mathrm{~cm}^{-1}$ indicates an $\mathrm{N}-\mathrm{H}$ bond, which can be associated with urea form aldehyde, DOC and PEI. A close comparison of the FTIR spectra confirms encapsulation of linalyl acetate in UFMCs and DOC in MLUFMCs. Furthermore, FTIR spectra also confirms the presence of UFMCs and MLUFMCs in SLSCs and PMLSCs without evident side reactions.

\section{Zeta potential measurements of microcapsules}

To confirm the polarity of layers on the MLUFMCs, zeta potential of each layer was determined, and the

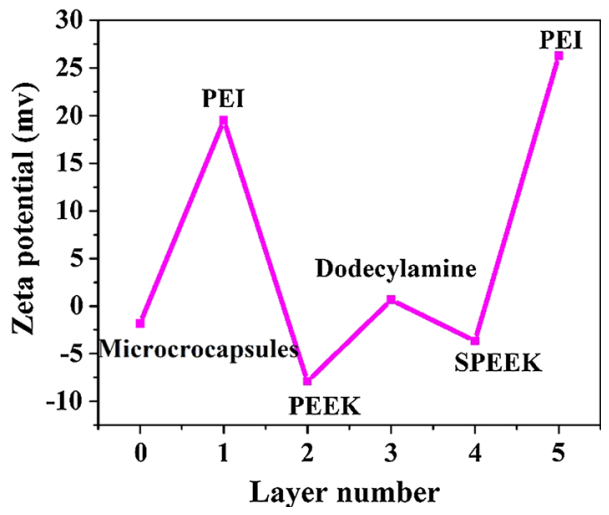

Figure 5 Zeta potential measurements of microcapsules. Layer number 0: microcapsules encapsulated with linalyl acetate (UFMCs) and layers 1-5, MLUFMCs having various polyelectrolyte layers. 
results are presented in Fig. 5 . It can be noticed that the zeta potential of the UFMCs is negative ( $-1.84 \mathrm{mV}$ ). However, when a PEI layer is formed on UFMCs the value of charge shifted to positive value $(\sim+20 \mathrm{mV})$ which indicates that the PEI layer carries a positive charge and thus can be easily bonded to the UFMCs. Furthermore, adsorption of SPEEK layer on PEI shifts the charge toward negative value $(\sim \mathrm{v}-10.0 \mathrm{mV})$ confirming its negative polarity. Owing to negatively charged (from the $-\mathrm{SO}_{3}$ group), the SPEEK layer can be easily bonded to the positively charged underneath PEI layer. Finally, shifting of the potential toward positive value $(\sim+1.0 \mathrm{mV})$ due to DOC indicates that it can be easily encapsulated between the SPEEK layers. It can be noticed from Fig. 5 that the surface charge varies according to the deposited layer (PEI, SPEEK, DOC) confirming the adsorption of the corresponding layer. Furthermore, zeta potential is increased by the addition of PEI (cation) on the surface and it decreased with the deposition of SPEEK (anion). A slight increase in zeta potential is observed after the addition of DOC leading to the successful adsorption of DOC. The obtained zeta potential results are consistent with results reported elsewhere [33].

\section{XPS analysis}

The XPS survey spectra recorded in the binding energy range of 250 to $800 \mathrm{eV}$ is shown in Fig. 6. XPS measurements with probe depths of up to $10 \mathrm{~nm}$ were performed. The major identified elements in the samples are carbon, oxygen and nitrogen. The presence of carbon, oxygen and nitrogen were expected from the chemical composition of the urea formaldehyde and polyethylenimine (PEI) in UFMCs and MLUFMCs, respectively. The high-resolution XPS spectra (C1s) for the UFMCs and MLUFMCs samples are also presented in inset (a) and (b) of Fig. 6, respectively. In C1s spectrum for the both type of samples, the peaks at 284.6 and 286.3 and $288.3 \mathrm{eV}$ refer to $\mathrm{C}-\mathrm{C}$ bond $\mathrm{C}-\mathrm{O}$ bond and $\mathrm{C}=\mathrm{O}$ bond, respectively [41]. The intensity of $\mathrm{C}-\mathrm{O}$ and $\mathrm{C}=\mathrm{O}$ bonds peaks in $\mathrm{C} 1 \mathrm{~s}$ spectrum have significantly been reduced after the adsorption of PEI on the surface of the microcapsules. The positions of the $\mathrm{C}-\mathrm{O}$ and $\mathrm{C}=\mathrm{O}$ are not very distinguishable in the encapsulated samples due to the peaks broadening. This indicated that the microcapsules have been encapsulated by the coated materials. As it is obvious from the molecular

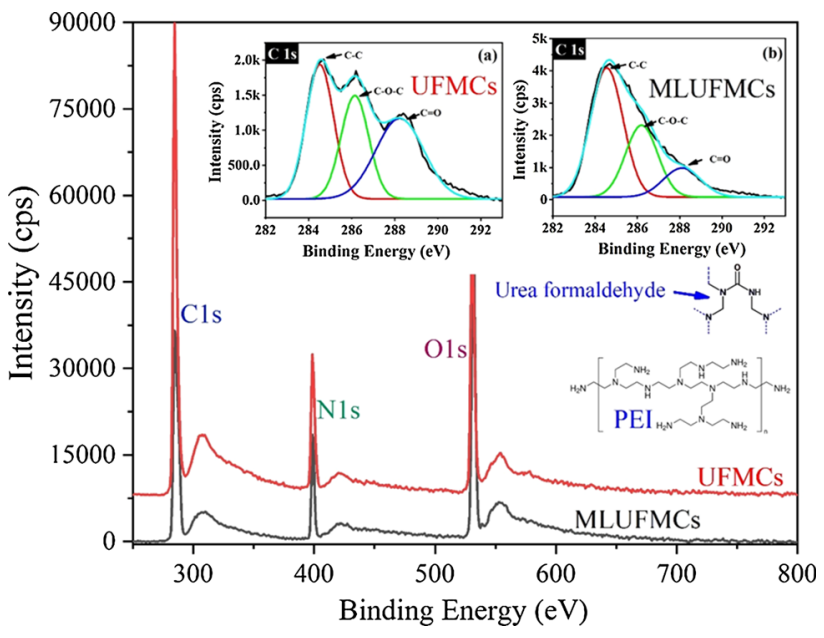

Figure 6 XPS survey spectra of UFMCs and MLUFMCs samples. Insets show the high-resolution XPS spectra C1s of the both UFMCs (a) and MLUFMCs (b) samples. Molecular structures of the urea formaldehyde and PEI are also given in the Figure.

structure of the PEI, it mainly consists of $\mathrm{C}-\mathrm{C}$ chains and there is no clear existence of $\mathrm{C}-\mathrm{O}$ and $\mathrm{C}=\mathrm{O}$ bonds when compared to the urea formaldehyde.

\section{FE-SEM/HR-TEM analysis}

of the encapsulated and multilayered microcapsules

Field emission scanning electron microscopy (FESEM) and high-resolution transmission electron microscopy (HR-TEM) analyses were conducted to study the morphology of the microcapsules (UFMCs, MLUFMCs) and the respective smart coatings (SLSCs, PMLSCs). Figure 7a shows the FE-SEM image of UFMCs. A spherical morphology of the UFMCs with mean diameter $36 \mu \mathrm{m}$ is observed without any crack and porosity. Moreover, a rough surface and variation in the size of microcapsules can also be noticed. In the in situ polymerization, the size of the microcapsules depends on the stirring rate [4] and it becomes finer with increasing stirring rate due to high shear force. The rough exterior surface improves the adhesion of the microcapsules to the coating matrix. The complete dryness, high tensile strength and low water absorbing capability of the urea-formaldehyde has led to the formation of more visible and isolated UFMCs. Figure $7 \mathrm{~b}$ shows the morphology of the MLUFMCs. These multilayered capsules have similar nodular morphology as UFMCs. A significant variation in the size of the 
Figure 7 FE-SEM analysis of microcapsules and smart coatings a UFMCs

b MLUFMCs, c SLSCs, d PMLSCs and e, f HR-TEM of MLUFMCs.
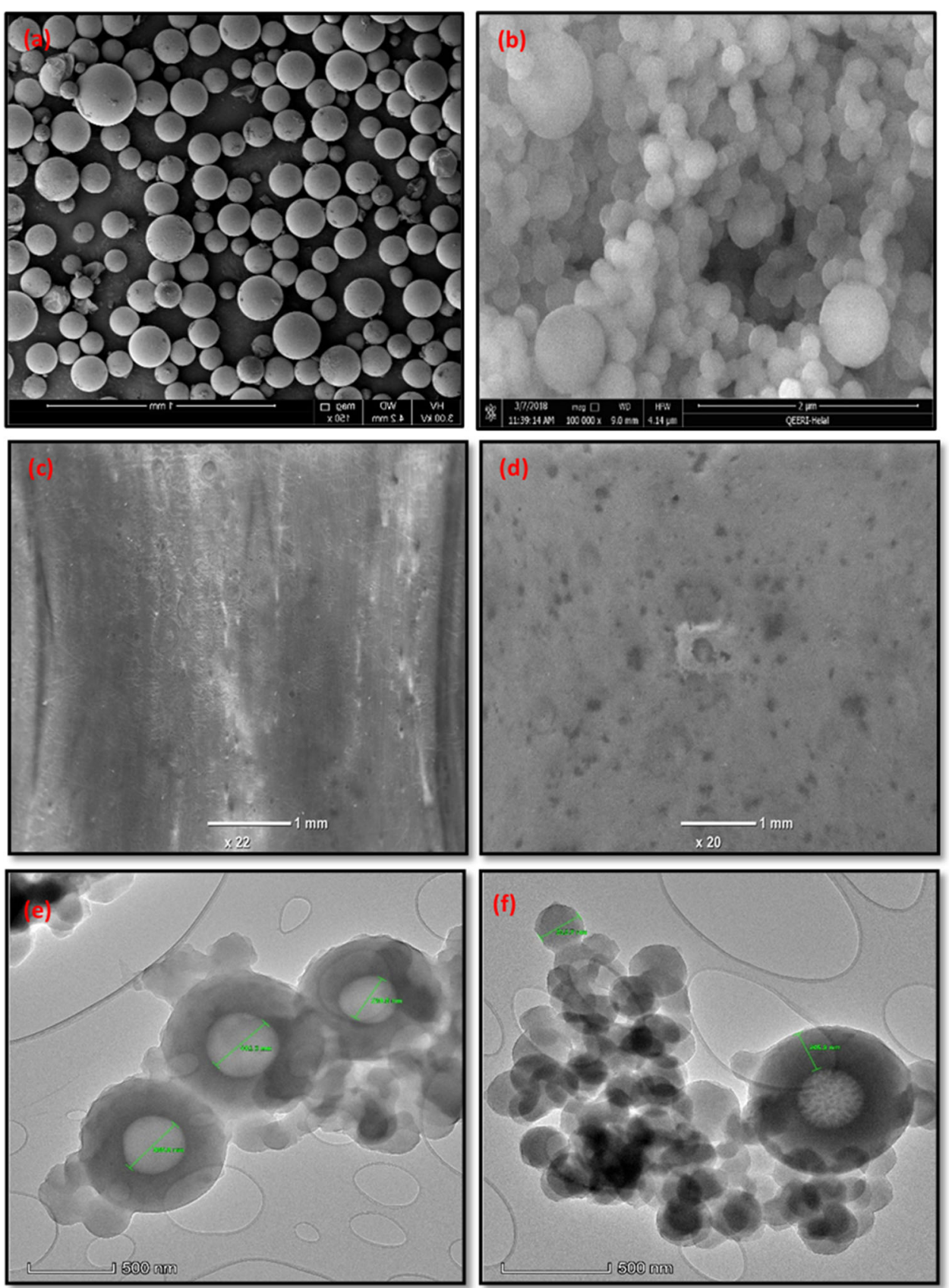

MLUFMCs capsules can also be noticed. A change in color may be related to the deposition of polyelectrolyte layers on the encapsulated UFMCs. However, a denser and more diffused structure is achieved in MLUFMCs as compared to UFMCs due to existence of multiple layers of polyelectrolyte materials. Figure 7c, d represents the structure of PMLSCs and SLSCs. It can be noticed that a dense, uniform, crack free and homogeneous structure is preserved in both kind of coatings. It can also be noticed that there are no pore and pin holes present in the coatings.
In order to have more insight of the developed MLUFMCs microcapsules, HR-TEM analysis was undertaken and the results are presented in Fig. 7e, f. It can be clearly noticed that well-defined multilayered nodular structure is preserved. The encapsulation of linalyl acetate and the presence of polyelectrolyte multilayers in MLUFMCs can be clearly noticed. The average core is $\sim 350 \mathrm{~nm}$, and the average thickness of polyelectrolyte multilayer is $\sim 206 \mathrm{~nm}$. The TEM analysis clearly confirms the formation of MLUFMCs. In TEM analysis, only 
smaller-size microcapsules were focused to study morphological features. However, it is pertinent to note that the average particle size of the synthesized MLUFMCs is $65 \mu \mathrm{m}$ as confirmed by our particle size analysis and discussed in the proceeding section.

\section{Particle size and XRD analysis of the microcapsules}

The particle size distribution of the microcapsules is further confirmed with particle size analyzer, and the results are shown in Fig. 8. It can be seen that the particle size of the UFMCs ranges from 0.01 to $500 \mu \mathrm{m}$. The majority of the UFMCs are made up of $10 \sim 63 \mu \mathrm{m}$, and the mean diameter of the UFMCs is found to be $36 \mu \mathrm{m}$. Our analysis indicates that the stirring rate of $1000 \mathrm{rpm}$ has resulted in UFMCs having average size of $36 \mu \mathrm{m}$. Figure 8 also shows the particle size distribution of MLUFMCs. It can be seen that the mean diameter of MLUFMCs is about $65 \mu \mathrm{m}$. The increase in the diameter of MLUFMCs indicates the deposition of polyelectrolyte layers and the inhibitor on the surface of the UFMCs. Furthermore, size variation in MLUFMCs can also be noticed and it is found that majority of the MLUFMCs are made up of size in the range of 10 to $125 \mu \mathrm{m}$. The mean diameter of MLUFMCs is found to be $65 \mu \mathrm{m}$. These results are consistent with our TEM analysis.

In order to study the effect of polyelectrolyte layers and the surface of microcapsules and the structural analysis of UFMCs and MLUFMCs, XRD analysis was also conducted. Figure 8 inset shows the XRD spectra revealing the amorphous behavior of the UFMCs and MLUFMCs. The peak at $17.5^{\circ}$ accounts

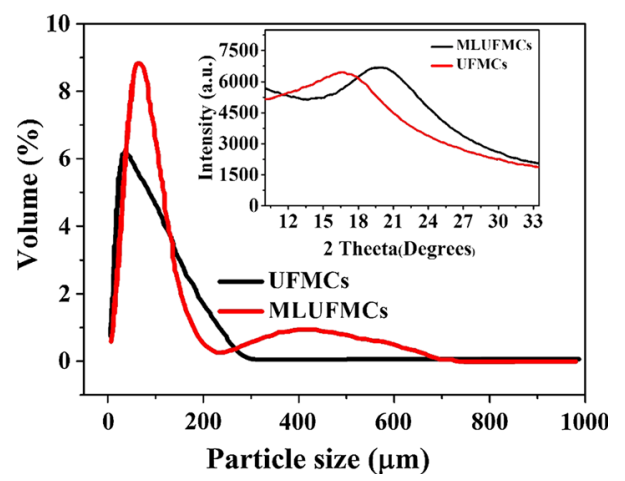

Figure 8 Particle size analysis of as-synthesized ureaformaldehyde microcapsules-UFMCs and multilayered ureaformaldehyde microcapsules-MLUFMCs. Inset shows the XRD of the UFMCs and MLUFMCs. for the presence of urea-formaldehyde present as the shell material of UFMCs encapsulated with linalyl acetate. Another peak at $22^{\circ}$ is observed, with higher intensity, which can be attributed to the deposited polyelectrolyte layers on the surface of UFMCs.

\section{Thermal stability of the microcapsules and epoxy coatings}

Thermal stability of encapsulated UFMCs, MLUFMCs, SLSCs and PMLSCs was analyzed using TGA, and the results are presented in Fig. $9(a, b)$. It is seen that both UFMCs and MLUFMCs experience a gradual weight loss with increasing temperature up to $600{ }^{\circ} \mathrm{C}$ (Fig. 9a). The initial weight loss (50 to $80^{\circ} \mathrm{C}$ ) may be associated with the removal of the absorbed moisture in the microcapsules. In the next region, the UFMCs show complete weight loss up to $200{ }^{\circ} \mathrm{C}$ due to encapsulated linalyl acetate (B.P, $220{ }^{\circ} \mathrm{C}$ ). However, the MLUFMCs exhibit better thermal stability which can be associated with the presence of high thermally stable polymeric structure (PEI and SPEEK) and dodecylamine. The drop around $200{ }^{\circ} \mathrm{C}$ could be due to the loss of sulfonic acid group of the SPEEK. These findings are consistent with previous studies [42]. Figure $9 \mathrm{~b}$ shows the TGA spectra of the SLSCs and PMLSCs. Like microcapsules, there is small weight loss at the first stage (50 to $80{ }^{\circ} \mathrm{C}$ ) for only the SLMCs, attributed to the presence of moisture in the coating. A comparison of Fig. 9a, b indicates that SLSCs and PMLSCs demonstrate better thermal stability compared to UFMCs, MLUFMCs which could be linked to the presence of polymeric matrices of the PEI and SPEEK and the long chain of dodecylamine.

\section{Measurement of self-releasing of DOC from MLUFMCs in response to $\mathrm{pH}$ change}

Figure 10 shows the release of DOC from the MLUFMCs in response to $\mathrm{pH}$ change. MLUFMCs were dipped into 0.1 molar $\mathrm{NaCl}$ solution having five different $\mathrm{pH}$ values $(2,5,7,9,11)$ and then $\mathrm{UV}-\mathrm{Vis}$ spectroscopy was under taken at each $\mathrm{pH}$ value for different time intervals (24, 48 and $72 \mathrm{~h}$ ). After $24 \mathrm{~h}$ of immersion of MLUFMCs in the solution, no absorption peak was detected at any $\mathrm{pH}$ value (Fig. 10a). However, after $48 \mathrm{~h}$ (Fig. 10b) of immersion, the absorption peak at $280 \mathrm{~nm}$ in $\mathrm{pH} 2$ indicates DOC release from the MLUFMCs. At this $\mathrm{pH}$, the $\mathrm{NH}_{2}$ of 
Figure 9 Thermal stability of a microcapsules-UFMCs, MLUFMCs and $\mathbf{b}$ developed smart coatings-SLSCs and PMLSCs.
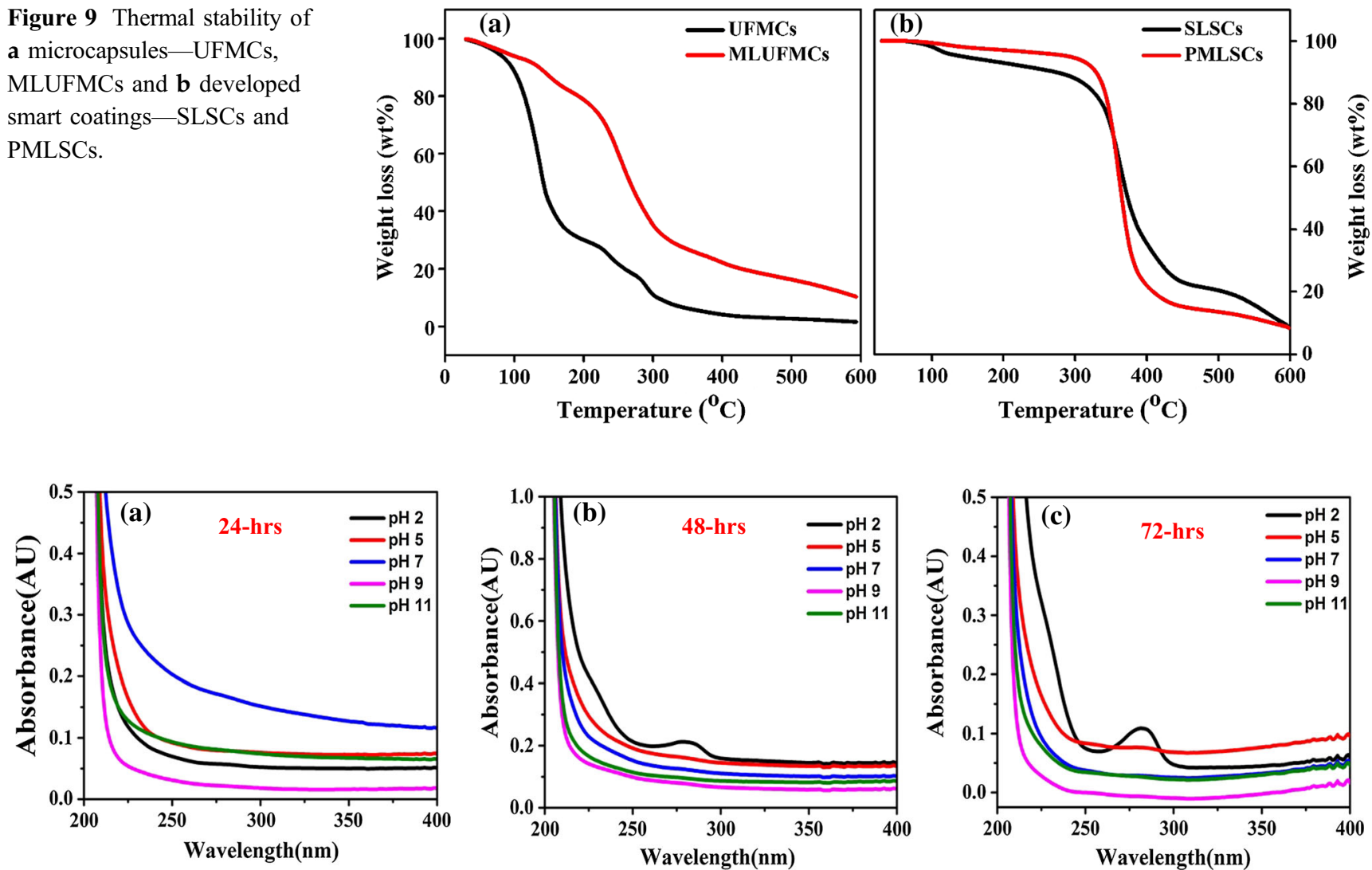

Figure $10 \mathrm{UV}-$ Vis spectra of the MLUFMCs immersed in $0.1 \mathrm{M} \mathrm{NaCl}$ solutions having various $\mathrm{pH}$ values after a $24 \mathrm{~h}$ b $48 \mathrm{~h}$ and c $72 \mathrm{~h}$.

DOC changes to $\mathrm{NH}_{3}{ }^{+}$which facilitates the release of DOC. After $72 \mathrm{~h}$ (Fig. 10c) in $\mathrm{pH} \mathrm{2,} \mathrm{the} \mathrm{intensity} \mathrm{of}$ the peak increased compared to $48 \mathrm{~h}$, which demonstrates an increase in the amount of inhibitor released with time. Thus, the results obtained at $\mathrm{pH} 2$ confirm that the release of the impregnated DOC in MLUFMCs is a time-dependent process. Furthermore, DOC release is $\mathrm{pH}$ sensitive, but the most efficient release was noticed only in acidic environment ( $\mathrm{pH}$ 2).

\section{Self-healing of smart coatings}

Figure 11 shows the self-healing ability of SLSCs and PMLSCs. The coatings were subjected to controlled damage. In response to the mechanical damage (creation of a scratch in the coatings), the microcapsules present in the coating matrix are ruptured and release the self-healing agent (linalyl acetate), which polymerizes in air and heals the scratch. Linalyl acetate has the ability to auto-oxidize when exposed to air, forming sensitizing hyperoxides as it contains oxidizable positions within its chemical structure. Hyperoxides, an epoxide and alcohol have been identified as oxidation products from linalyl acetate. However, 6,7-epoxy-3,7-dimethylocta-1,5-diene-3yl acetate is identified as the secondary oxidation product [43, 44]. A comparison of Fig. 11a, d indicates that after $24 \mathrm{~h}$ SLSCs have healed significantly, whereas the PMLSCs were partially self-healed. This observation suggests that the self-healing ability of SLSCs is superior to PMLSCs. This is due to the higher amount of self-healing agent (linalyl acetate) present in the UFMCs. It is pertinent to note that SLCs contain UFMCs which are encapsulated with linalyl acetate only, while the PMLSCs have linalyl acetate in the core and loaded dodecylamine in the layers as well. So, with the same weight percent of encapsulated UFMCs (5 wt $\%$ ) and MLUFMCs (5 wt $\%)$, SLSCs have more amount of self-healing agent (linalyl acetate) when compared to PMLSCs (because of the only linalyl acetate as a core material in UFMCs) and thus shows better self-healing performance. These findings are consistent with previous 


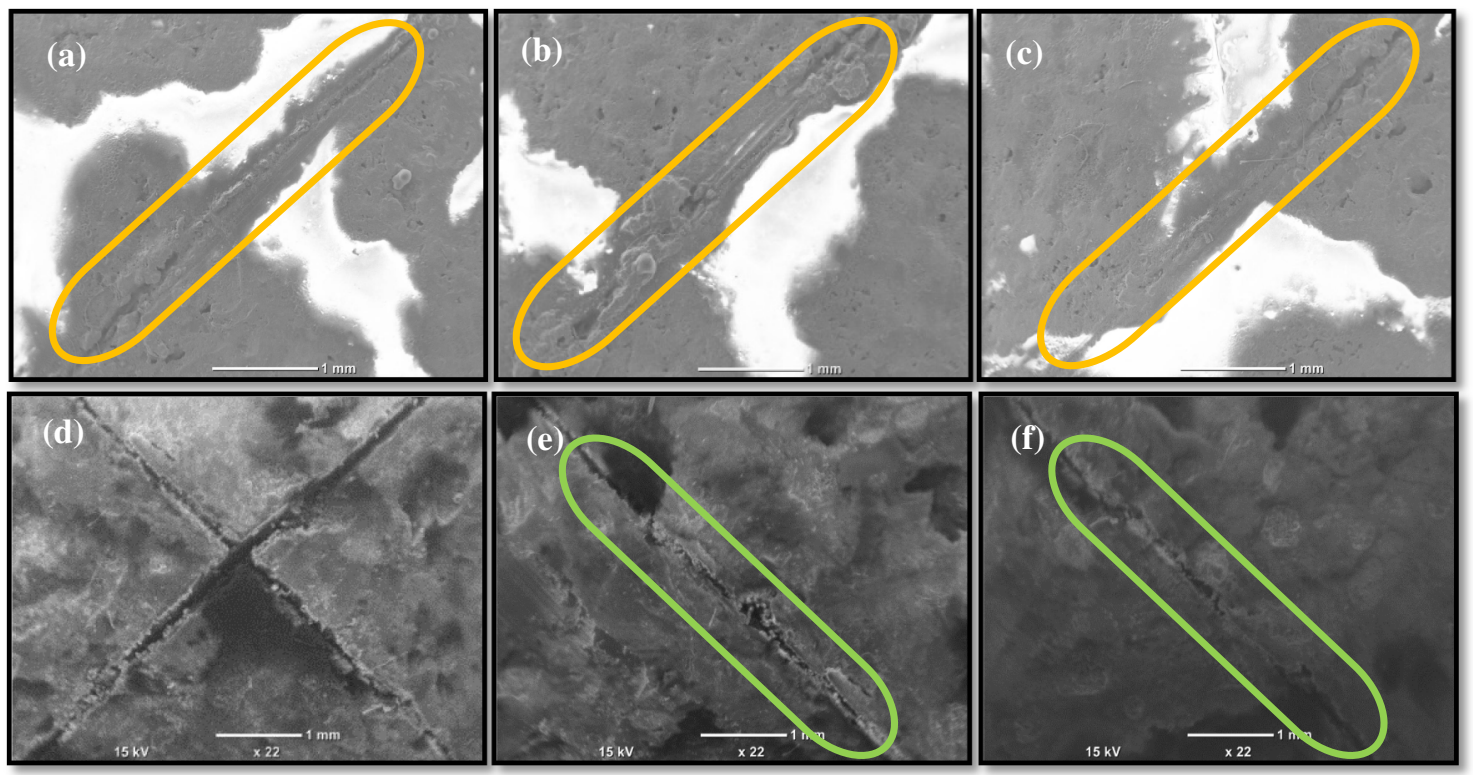

Figure 11 SEM images of the scratched samples (a, b, c) SLSCs after 24, 48 and $72 \mathrm{~h}$. and (d, e, f) PMLSCs after 24,42 and $72 \mathrm{~h}$.

results $[4,45]$. However, it is worth to note that after $72 \mathrm{~h}$, the PMLSCs have also been self-healed as shown in Fig. 11e, f demonstrating successful healing effect.

\section{Electrochemical Impedance Spectroscopy (EIS)}

EIS analysis was performed to investigate the anticorrosive and consequently the corrosion healing performance of the prepared coatings. The EIS measurements were carried out after the immersion of the scratched samples in $3.5 \mathrm{wt} \% \mathrm{NaCl}$ solution for 2, 24 and $48 \mathrm{~h}$ at room temperature. Bode plots for PECs, SLSCs and PMLSCs are depicted in Fig. 12.

Figure 12 show that EIS spectra have a similar shape. Therefore, all coatings seem to display an identical number of time constants that were fitted with an equivalent electric circuit of the two-time constants with mass-controlled diffusion-Fig. 13. $R_{\mathrm{s}}$ is the solution resistance, $R_{\mathrm{po}}$ is the pore resistance in the intact parts of the coating, $R_{\text {ct }}$ represents the charge transfer resistance at the steel interface (pores and scratched areas). The constant phase elements related to double layer capacitance and coating capacitance are represented by $\mathrm{CPE}_{\mathrm{dl}}$ and $\mathrm{CPE}_{\mathrm{c}}$, respectively. The Warburg diffusion element $(W)$ illustrates the presence of mass transport. The combination of $C P E_{\mathrm{dl}}$ and $R_{\mathrm{ct}}$ was used to fit the lowfrequency time constant and can be assigned to the steel/coating interface. The high-frequency time constant $\left(\mathrm{CPE}_{\text {coat }}\right.$ and $\left.R_{\mathrm{po}}\right)$ accounts for the barrier properties of the coated areas.

Table 1 contains the charge transfer resistance values acquired from fitting the measured EIS data of the coatings. Figure $12 \mathrm{a}, \mathrm{b}$ and Table 1 reveal that after $2 \mathrm{~h}$ of immersion, the SLSCs and PMLSCs show higher values of $R_{\mathrm{ct}}$, i.e., $10.3 \times 10^{4}$ and $81.9 \times 10^{3}$ $\Omega \mathrm{cm}^{2}$, respectively, compared to the PECs samples $\left(43.1 \times 10^{3} \Omega \mathrm{cm}^{2}\right)$. The higher $R_{\mathrm{ct}}$ values of the SLSCs and PMLSCs indicate better corrosion protection of both coatings. This effect is probably related to rupture of the microcapsules during scratching and release of linalyl acetate that, in turn, is oxidized by the atmospheric oxygen, which results in healing the scratched area of the coating by formation of a stable film as explained above in Sect. 3.8. However, the lower $R_{\mathrm{ct}}$ value of PMLSCs, as shown in Table 1, might be related to the complex layered structure of PLUFMCs, which slows down the release of linalyl acetate from the microcapsules and the inhibitor.

PECs sample shows a lower $R_{\mathrm{ct}}$ value of $20.6 \times 10^{3}$ $\Omega \mathrm{cm}^{2}$ after $24 \mathrm{~h}$ (Fig. 12c) compared to the corresponding value after $2 \mathrm{~h}$, which keeps decreasing upon prolongation of the immersion time (up to $48 \mathrm{~h}$ )-Fig. 12e and Table 1. This expected trend is due to continuous corrosion activity as no inhibitor or healing agent is present. The $R_{\mathrm{ct}}$ value obtained for the SLSCs increases by about $67 \%$ after $24 \mathrm{~h}$ immersion, while that of the PMLSCs rises by about $82 \%$ 
Figure 12 (a, c, e) Bode and $(\mathbf{b}, \mathbf{d}, \mathbf{f})$ the corresponding phase angle plots for the scratched coated specimens with PECs (epoxy resin only), SLSCs (epoxy loaded with 5 $w \mathrm{t} \%$ of the UFMCs) and PMLSCs (epoxy loaded with 5 $\mathrm{wt} \%$ of the MLUFMCs) after immersion in $3.5 \mathrm{wt} \% \mathrm{NaCl}$ solution at room temperature for 2,24 and $48 \mathrm{~h}$, respectively.

Figure 13 Electrochemical equivalent electric circuit obtained from fitting the impedance data.
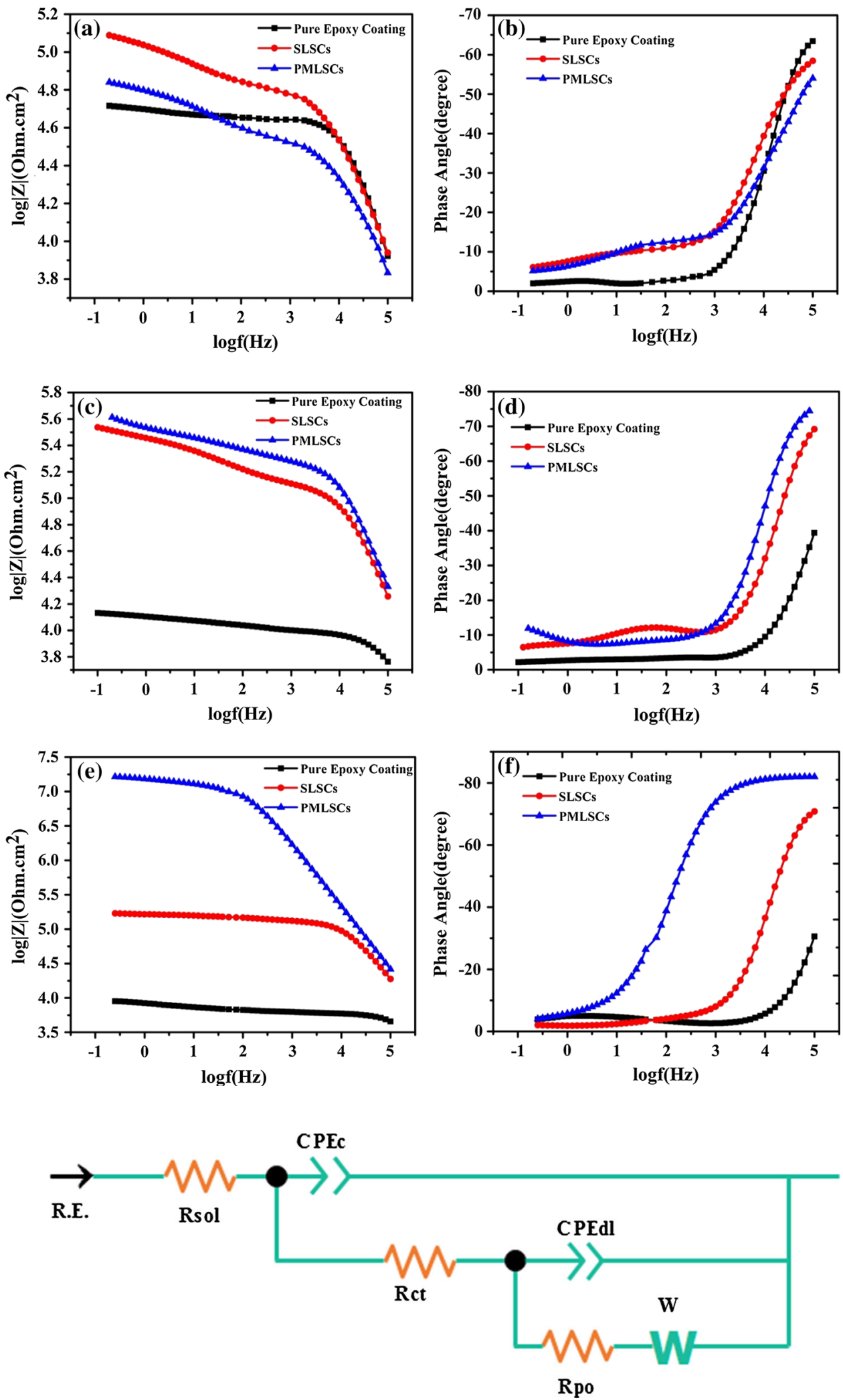

(see Fig. 12c and Table 1). The higher $R_{\mathrm{ct}}$ value for the coating containing the multilayered capsules indicates that the corrosion inhibitor, and the self-healing agent encapsulated in the multilayers of the synthesized capsules were released as consequence of the scratch and local $\mathrm{pH}$ acidification caused by 
Table 1 Electrochemical parameters obtained by fitting the measured impedance data shown in Fig. 12 of the scratched coated specimens immersed in $3.5 \mathrm{wt} \% \mathrm{NaCl}$ solution

\begin{tabular}{lcc}
\hline Coatings & Time $(\mathrm{h})$ & $R_{\mathrm{ct}}\left(\Omega \mathrm{cm}^{2}\right)$ \\
\hline PECs & 2 & $43.1 \times 10^{3}$ \\
SLSCs & & $10.3 \times 10^{4}$ \\
PMLSCs & \multirow{2}{*}{24} & $81.9 \times 10^{3}$ \\
PECs & & $20.6 \times 10^{3}$ \\
SLSCs & & $31.5 \times 10^{4}$ \\
PMLSCs & 48 & $46.8 \times 10^{4}$ \\
PECs & & $10.8 \times 10^{3}$ \\
SLSCs & & $12.2 \times 10^{4}$ \\
PMLSCs & & $25.2 \times 10^{6}$ \\
\hline
\end{tabular}

hydrolysis of iron ions released due to corrosion. It can be noticed that the PMLSCs show further increase in the $R_{\mathrm{ct}}$ value, with a major shift in the phase angle compared to the corresponding value after $24 \mathrm{~h}$ of immersion due to further release of corrosion inhibitor (dodecylamine) to the scratched area leading to inhibition of the corrosion activity. The higher $R_{\mathrm{ct}}$ value $\left(25.2 \times 10^{6} \Omega \mathrm{cm}^{2}\right)$ can be attributed to effective release of inhibitor and simultaneous formation of the healing film.
The charge transfer resistance is increasing in the SLSCs and PMLSCs with time (from $2 \mathrm{~h}$ of immersion to $24 \mathrm{~h}$ ) due to the release of dodecylamine as well as release of linalyl acetate, both forming protective species. The $R_{\mathrm{ct}}$ values showed further increase for the PMLSCs compared to SLSCs due to the double action of the PMLSCs coatings that comes from the polymer healing effect and corrosion inhibition of steel. In fact, the damaged area, even after healing by linalyl acetate, still contains some microdefects and may not avoid totally the corrosion activity. Hence, after $24 \mathrm{~h}$ of the scratch the corrosion process slowly progresses, and the $\mathrm{pH}$ of the surrounding medium acidifies due to hydrolysis of $\mathrm{Fe}$ cations and effect that stimulates the release of dodecylamine from the polyelectrolyte layers. The results obtained in the present work are in line with the previous reported literature [33, 35].

A comparison of the anticorrosive properties of the coatings developed within this work with those already reported literature is presented in Table 2 . The comparative analysis demonstrates that the coatings developed in the present work possess superior anti-corrosive performance, an effect that can be attributed to the novel chemistry of the polyelectrolyte multilayered urea formaldehyde

Table 2 Comparison of the present coatings with the previous results in terms of corrosion impedance values

\begin{tabular}{|c|c|c|c|c|}
\hline S.No. & Coatings & Immersion time & $\mathrm{R}_{\mathrm{ct}}(\Omega)$ & Reference \\
\hline \multirow[t]{3}{*}{1} & Blank Epoxy & $\begin{array}{l}2 \mathrm{~h} . \\
24 \mathrm{~h} \\
48 \mathrm{~h}\end{array}$ & $\begin{array}{l}4.3 \times 10^{4} \\
2.0 \times 10^{4} \\
1.0 \times 10^{4}\end{array}$ & \multirow[t]{3}{*}{ Present work } \\
\hline & Epoxy with UF microcapsules & $\begin{array}{l}2 \mathrm{~h} \\
24 \mathrm{~h} \\
48 \mathrm{~h}\end{array}$ & $\begin{array}{l}1.0 \times 10^{5} \\
3.1 \times 10^{5} \\
1.2 \times 10^{5}\end{array}$ & \\
\hline & $\begin{array}{l}\text { Epoxy with multilayered microcapsules } \\
\text { (UF/PEI/SPEEK/DOC/SPEEK/PEI) }\end{array}$ & $\begin{array}{l}2 \mathrm{~h} \\
24 \mathrm{~h} \\
48 \mathrm{~h}\end{array}$ & $\begin{array}{l}8.1 \times 10^{4} \\
4.6 \times 10^{5} \\
2.5 \times 10^{7}\end{array}$ & \\
\hline 2 & $\begin{array}{l}\text { Blank epoxy } \\
\text { Epoxy with UF microcapsules }\end{array}$ & $\begin{array}{l}7 \mathrm{~h} \\
7 \mathrm{~h}\end{array}$ & $\begin{array}{l}1.4 \times 10^{3} \\
8.9 \times 10^{4}\end{array}$ & Fayyad et al. [4] \\
\hline \multirow[t]{3}{*}{3} & Blank Epoxy & $\begin{array}{l}2 \mathrm{~h} \\
24 \mathrm{~h}\end{array}$ & $\begin{array}{l}7.5 \times 10^{3} \\
4.7 \times 10^{3}\end{array}$ & \multirow[t]{3}{*}{ Abrantes et al. [33] } \\
\hline & Epoxy with UF microcapsules & $\begin{array}{l}2 \mathrm{~h} \\
24 \mathrm{~h}\end{array}$ & $\begin{array}{l}1.9 \times 10^{4} \\
1.2 \times 10^{4}\end{array}$ & \\
\hline & $\begin{array}{l}\text { Epoxy with multilayered microcapsules } \\
\text { (UF/PEI/PSS/BTZ/PSS/PEI) }\end{array}$ & $\begin{array}{l}2 \mathrm{~h} \\
24 \mathrm{~h}\end{array}$ & $\begin{array}{l}1.1 \times 10^{4} \\
3.5 \times 10^{4}\end{array}$ & \\
\hline \multirow[t]{2}{*}{4} & Blank epoxy & $\begin{array}{l}24 \mathrm{~h} \\
48 \mathrm{~h}\end{array}$ & $\begin{array}{l}1.4 \times 10^{5} \\
6.6 \times 10^{4}\end{array}$ & \multirow[t]{2}{*}{ Liu et al. [35] } \\
\hline & Epoxy with $\mathrm{CeO}_{2}$ capsules & $\begin{array}{l}24 \mathrm{~h} \\
48 \mathrm{~h}\end{array}$ & $\begin{array}{l}4 \times 10^{5} \\
7.4 \times 10^{5}\end{array}$ & \\
\hline
\end{tabular}


microcapsules, selection of the selected inhibitor, selfhealing agent and their efficient release in response to the external stimuli. The two protective mechanisms are independently and simultaneously occurring in the developed coatings and hence increasing the corrosion protection performance of the smart coatings. The enhanced anticorrosion performance makes this composite coating an interesting option to protect steel components used in the oil and gas as well as other related industries.

\section{Conclusion}

Single-layer smart coatings (SLSCs) and polyelectrolyte multilayered smart coatings (PMSCs) were prepared from urea formaldehyde capsules loaded with linalyl acetate and capsules loaded with linalyl acetate and containing dodecylamine, respectively. It can be concluded that PMLSCs demonstrate improved thermal and superior anticorrosion properties compared to SLSCs. This enhancement can be attributed to the efficient release of the encapsulated self-healing species, linalyl acetate and corrosion inhibitor (dodecylamine) entrapped in polyelectrolyte layers from the MLUFMCs. Owing to the good thermal and enhanced anticorrosion properties, the novel PMLSCs may be attractive for designing of functional coatings for corrosion protection of steel parts.

\section{Acknowledgements}

Open Access funding provided by the Qatar National Library. This publication was made possible by NPRP Grant 9-080-2-039 from Qatar National Research Fund (a member of the Qatar Foundation). Statements made herein are solely the responsibility of the authors. R. A. Shakoor would like to acknowledge the financial support of QU internal grant-QUCG-CAM-2018/2019-3 and the Core Labs, QEERI for their SEM and TEM imaging. M.F. Montemor thanks Fundação para a Ciência e a Tecnologia (FCT, Portugal) for financial support under the projects PEst-OE/QUI/UI0100/2013.

\section{Compliance with ethical standards}

Conflict of interest The authors declare that they have no conflict of interest.
Open Access This article is distributed under the terms of the Creative Commons Attribution 4.0 International License (http://creativecommons.org/ licenses/by/4.0/), which permits unrestricted use, distribution, and reproduction in any medium, provided you give appropriate credit to the original author(s) and the source, provide a link to the Creative Commons license, and indicate if changes were made.

\section{References}

[1] Philip A, Schweitzer PE (2005) Paint and coatings: applications and corrosion resistance, 1st edn. CRC Press, Boca Raton

[2] Revie RW, Uhlig HH (2008) Corrosion and corrosion control corrosion and an introduction to corrosion science and engineering, 4th edn. Wiley, Hoboken

[3] Montemor MF (2014) Functional and smart coatings for corrosion protection: a review of recent advances. Surf Coat Technol 258:17-37

[4] Fayyad EM, Almaadeed MA, Jones A (2015) Encapsulation of tung oil for self-healing coatings in corrosion applications. Sci Adv Mater 7:2628-2638. https://doi.org/10.1166/sam.2 015.2583

[5] Shchukin DG, Zheludkevich M, Yasakau K et al (2006) Layer-by-layer assembled nanocontainers for self-healing corrosion protection. Adv Mater 18:1672-1678. https://doi. org/10.1002/adma.200502053

[6] Safaei F, Khorasani SN, Rahnama H, Neisiany RE (2018) Progress in organic coatings single microcapsules containing epoxy healing agent used for development in the fabrication of cost efficient self-healing epoxy coating. Prog Org Coatings 114:40-46. https://doi.org/10.1016/j.porgcoat.2017.09. 019

[7] Shchukin DG, Möhwald H (2007) Self-repairing coatings containing active nanoreservoirs. Small 3:926-943. https://d oi.org/10.1002/smll.200700064

[8] White SR, Sottos NR, Geubelle PH et al (2001) Autonomic healing of polymer composites. Nature 409:794-797. http s://doi.org/10.1038/35057232

[9] Falcón JM, Batista FF, Aoki IV (2014) Encapsulation of dodecylamine corrosion inhibitor on silica nanoparticles. Electrochim Acta 124:109-118. https://doi.org/10.1016/j.ele ctacta.2013.06.114

[10] Kartsonakis IA, Danilidis IL, Pappas GS, Kordas GC (2010) Encapsulation and release of corrosion inhibitors into titania nanocontainers. J Nanosci Nanotechnol 10:5912-5920. http s://doi.org/10.1166/jnn.2010.2571 
[11] Feng Y, Cheng YF (2017) An intelligent coating doped with inhibitor-encapsulated nanocontainers for corrosion protection of pipeline steel. Chem Eng J 315:537-551. https://doi. org/10.1016/j.cej.2017.01.064

[12] Mahidashti Z, Shahrabi T, Ramezanzadeh B (2018) The role of post-treatment of an ecofriendly cerium nanostructure conversion coating by green corrosion inhibitor on the adhesion and corrosion protection properties of the epoxy coating. Prog Org Coatings 114:19-32. https://doi.org/10.1 016/j.porgcoat.2017.09.015

[13] Van Soestbergen M, Baukh V, Erich SJF et al (2014) Release of cerium dibutylphosphate corrosion inhibitors from highly filled epoxy coating systems. Prog Org Coatings 77:1562-1568. https://doi.org/10.1016/j.porgcoat.2013.12. 018

[14] Calado LM, Taryba MG, Carmezim MJ, Montemor MF (2018) Corros Sci. https://doi.org/10.1016/j.corsci.2018.06. 013

[15] Lang S, Zhou Q (2017) Synthesis and characterization of poly(urea-formaldehyde) microcapsules containing linseed oil for self-healing coating development. Prog Org Coatings 105:99-110. https://doi.org/10.1016/j.porgcoat.2016.11.015

[16] Suryanarayana C, Rao KC, Kumar D (2008) Preparation and characterization of microcapsules containing linseed oil and its use in self-healing coatings. Prog Org Coatings 63:72-78. https://doi.org/10.1016/j.porgcoat.2008.04.008

[17] Huang M, Zhang H, Yang J (2012) Synthesis of organic silane microcapsules for self-healing corrosion resistant polymer coatings. Corros Sci 65:561-566. https://doi.org/10. 1016/j.corsci.2012.08.020

[18] Soo B, Cho H, White SR, Braun PV (2009) Self-healing polymer coatings. Adv mater. https://doi.org/10.1002/adma. 200802008

[19] Liu X, Zhang H, Wang J et al (2012) Preparation of epoxy microcapsule based self-healing coatings and their behavior. Surf Coat Technol 206:4976-4980. https://doi.org/10.1016/j. surfcoat.2012.05.133

[20] Wei H, Wang Y, Guo J et al (2015) Advanced micro/nanocapsules for self-healing smart anticorrosion coatings. J Mater Chem A 3:469-480. https://doi.org/10.10 39/c4ta04791e

[21] Shchukin DG, Grigoriev DO, Möhwald H (2010) Application of smart organic nanocontainers in feedback active coatings. Soft Matter 6:720-725. https://doi.org/10.1039/b $918437 f$

[22] Glinel K, Déjugnat C, Prevot M et al (2007) Responsive polyelectrolyte multilayers. Colloids Surf A Physicochem Eng Asp 303:3-13. https://doi.org/10.1016/j.colsurfa.2007. 02.052
[23] Lamaka SV, Shchukin DG, Andreeva DV et al (2008) Solgel/polyelectrolyte active corrosion protection system. Adv Funct Mater 18:3137-3147. https://doi.org/10.1002/adfm. 200800630

[24] Funke W (1997) Progress in organic coatings problems and progress in organic coatings science and technology'. Prog Org Coatings 31:5-9. https://doi.org/10.1016/S0300-9440(9 7)00013-1

[25] Andreeva DV, Fix D, Möhwald H, Shchukin DG (2008) Self-healing anticorrosion coatings based on $\mathrm{pH}$-sensitive polyelectrolyte/inhibitor sandwichlike nanostructures. Adv Mater 20:2789-2794. https://doi.org/10.1002/adma. 200800705

[26] Snihirova D, Lamaka SV, Montemor MF (2012) "SMART" protective ability of water based epoxy coatings loaded with $\mathrm{CaCO}_{3}$ microbeads impregnated with corrosion inhibitors applied on AA2024 substrates. Electrochim Acta 83:439-447. https://doi.org/10.1016/j.electacta.2012.07.102

[27] Shchukin DG, Lamaka SV, Yasakau KA et al (2008) Active anticorrosion coatings with halloysite nanocontainers. J Phys Chem C 112:958-964. https://doi.org/10.1021/jp076188r

[28] Lvov YM, Shchukin DG, Mohwald H, Price RR (2008) Halloysite clay nanotubes for controlled release of protective agents. ACS Nano 2:814-820

[29] Mahulikar PP, Jadhav RS, Hundiwale DG (2011) Performance of polyaniline $/ \mathrm{TiO}_{2}$ nanocomposites in epoxy for corrosion resistant coatings. Iran Polym J 20:367-376

[30] Balaskas AC, Kartsonakis IA, Tziveleka LA, Kordas GC (2012) Improvement of anti-corrosive properties of epoxycoated AA 2024-T3 with $\mathrm{TiO}_{2}$ nanocontainers loaded with 8-hydroxyquinoline. Prog Org Coatings 74:418-426. http s://doi.org/10.1016/j.porgcoat.2012.01.005

[31] Poornima Vijayan P, Al-Maadeed MASA (2016) $\mathrm{TiO}_{2}$ nanotubes and mesoporous silica as containers in self-healing epoxy coatings. Sci Rep 6:1-9. https://doi.org/10.1038/sre p38812

[32] Montemor MF, Snihirova DV, Taryba MG et al (2012) Evaluation of self-healing ability in protective coatings modified with combinations of layered double hydroxides and cerium molibdate nanocontainers filled with corrosion inhibitors. Electrochim Acta 60:31-40. https://doi.org/10.10 16/j.electacta.2011.10.078

[33] Abrantes D, Riegel-vidotti IC, Guerreiro M et al (2018) Smart coating based on double stimuli-responsive microcapsules containing linseed oil and benzotriazole for active corrosion protection. Corros Sci 130:56-63. https://doi.org/ 10.1016/j.corsci.2017.10.009

[34] Sonawane SH, Bhanvase BA, Jamali AA et al (2012) Improved active anticorrosion coatings using layer-by-layer assembled $\mathrm{ZnO}$ nanocontainers with benzotriazole. Chem 
Eng J 189-190:464-472. https://doi.org/10.1016/j.cej.2012. 02.076

[35] Liu X, Gu C, Wen Z, Hou B (2018) Improvement of active corrosion protection of carbon steel by water-based epoxy coating with smart $\mathrm{CeO}_{2}$ nanocontainers. Prog Org Coatings 115:195-204. https://doi.org/10.1016/j.porgcoat.2017.10. 015

[36] Tan C, Selig MJ, Lee MC, Abbaspourrad A (2018) Polyelectrolyte microcapsules built on $\mathrm{CaCO}_{3}$ scaffolds for the integration, encapsulation, and controlled release of copigmented anthocyanins. Food Chem 246:305-312. https://doi. org/10.1016/j.foodchem.2017.11.033

[37] Abu-Thabit NY, Hamdy AS (2016) Stimuli-responsive Polyelectrolyte Multilayers for fabrication of self-healing coatings - a review. Surf Coatings Technol 303:406-424. h ttps://doi.org/10.1016/j.surfcoat.2015.11.020

[38] Brown EN, Kessler MR, Sottos NR, White SR (2003) In situ poly (urea-formaldehyde) microencapsulation of dicyclopentadiene. J Microencapsul 20:719-730

[39] Beck HN (1992) Solubility characteristics of poly (Etheretherketone) and poly (phenylene sulfide). J Appl Polym Sci 45:1361-1366

[40] Cai J, Lin P, Zhu X, Su Q (2006) Comparative analysis of clary sage (S. sclarea L.) oil volatiles by GC-FTIR and GCMS. Food Chem 99:401-407. https://doi.org/10.1016/j.food chem.2005.07.041
[41] Ahmad Z, Najeeb MA, Shakoor RA et al (2017) Instability in $\mathrm{CH}_{3} \mathrm{NH}_{3} \mathrm{PbI}_{3}$ perovskite solar cells due to elemental migration and chemical composition changes. Sci Rep 7:15406-15414. https://doi.org/10.1038/s41598-017-158414

[42] Liu X, Sheng X, Lee JK, Kessler MR (2009) Synthesis and characterization of melamine- urea-formaldehyde microcapsules containing ENB-based self-healing agents. Macromol Mater Eng 294:389-395. https://doi.org/10.1002/mame. 200900015

[43] Sköld M, Hagvall L, Karlberg A-T (2008) Autoxidation of linalyl acetate, the main component of lavender oil, creates potent contact allergens. Contact Dermatitis 58:9-14

[44] Hagvall L, Berglund V, Christensson JB (2015) Air-oxidized linalyl acetate - an emerging fragrance allergen. Contact Dermatitis 2:216-223. https://doi.org/10.1111/cod.12350

[45] Hatami Boura S, Peikari M, Ashrafi A, Samadzadeh M (2012) Self-healing ability and adhesion strength of capsule embedded coatings - micro and nano sized capsules containing linseed oil. Prog Org Coatings 75:292-300. https://d oi.org/10.1016/j.porgcoat.2012.08.006

Publisher's Note Springer Nature remains neutral with regard to jurisdictional claims in published maps and institutional affiliations. 